\title{
Marcadores RAPD para detecção de resistência à ferrugem-asiática-da-soja
}

\author{
Marcelo Marchi Costa(1), Sandra Helena Unêda-Trevisoli(2), José Baldin Pinheiro(3), \\ Romeu Afonso de Souza Kiihl(4), Éberson Sanches Calvo(4) e Antonio Orlando Di Mauro(1)
}

(1)Universidade Estadual Paulista, Faculdade de Ciências Agrárias e Veterinárias, Departamento de Produção Vegetal, Via de Acesso Prof. Paulo Donato Castellane, s/no, CEP 14884-900 Jaboticabal, SP. E-mail: mmarchi@hotmail.com, orlando@fcav.unesp.br ${ }^{(2)}$ Faculdade de Tecnologia de Jaboticabal, Via de Acesso Prof. Paulo Donato Castellane, s/no, CEP 14884-900 Jaboticabal, SP. E-mail: sahuneda@hotmail.com ${ }^{(3)}$ Universidade de São Paulo, Escola Superior de Agricultura Luiz de Queiroz, Departamento de Genética, Avenida Pádua Dias, № 11, CEP 13418-900 Piracicaba, SP. E-mail: baldin@esalq.usp.br (4)Tropical Melhoramento e Genética Ltda., Rodovia Celso Garcia Cid, Km 87, CEP 86183-600 Cambé, PR. E-mail: romeu@tmg.agr.br, ebersoncalvo@tmg.agr.br

Resumo - Os objetivos deste trabalho foram confirmar a herança da resistência da PI 459025 (Rpp4) à ferrugemasiática-da-soja e identificar marcadores moleculares do tipo RAPD, ligados a este gene de resistência, em populações de soja. Pelo cruzamento dos genitores contrastantes PI 459025 x Coodetec 208 obteve-se uma população, cujas populações das gerações $\mathrm{F}_{2}$ e $\mathrm{F}_{2: 3}$ foram artificialmente infectadas e avaliadas quanto à reação ao fungo Phakopsora pachyrhizi, pelo tipo de lesão (RB - resistente e TAN - suscetível). Com os resultados da avaliação fenotípica, dois "bulks" foram obtidos com DNA de plantas homozigóticas resistentes e suscetíveis, respectivamente, pela análise de "bulks" segregantes. De 600 iniciadores RAPD aleatórios, foram identificados três com fragmentos polimórficos entre os "bulks" e parentais contrastantes quanto à resistência. Pela análise do qui-quadrado, confirmaram-se: a herança monogênica, com dominância completa quanto à resistência ao patógeno, e a segregação 3:1 para a presença de banda dos três marcadores. Os três marcadores são ligados respectivamente a 5,1, 6,3 e 14,7 cM de distância do loco de resistência, em fase de repulsão no grupo de ligação G, o que foi confirmado pela utilização do marcador microssatélite Satt288. Estes marcadores são promissores na seleção assistida para resistência à ferrugem-asiática-da-soja.

Termos para indexação: Glycine max, Phakopsora pachyrhizi, marcadores moleculares, seleção assistida.

\section{RAPD markers for detection soybean rust resistance}

\begin{abstract}
The objectives of this work were to confirm the PI 459025 inheritance of resistance (Rpp4) to Asian soybean rust pathogen and to detect RAPD markers linked to this resistance gene in soybean populations. Through the cross of the distint parental lines PI 459025 x Coodetec 208, a population was obtained, whose $\mathrm{F}_{2}$ and $\mathrm{F}_{2: 3}$ generations had their populations artificially infected and evaluated for the reaction to Phakopsora pachyrhizi, by lesion type classification (RB - resistant and TAN - susceptible). Using the phenotypic results, the bulked segregant analysis was performed and two DNA bulks were obtained from homozygous resistant and homozygous susceptible plants, respectively. Out of the 600 random RAPD primers analyzed, three were identified as polymorphic fragments related to resistance, between contrasting bulks and parents. Through chi-square test, confirmations were obtained for the monogenic inheritance, with complete dominance segregation for resistance to the pathogen, and the 3:1 segregation of band presence for the markers. The three markers are linked to the resistance locus, in repulsion phase, at 5.1, 6.3 and $14.7 \mathrm{cM}$ from it, in the linkage group G, which was confirmed by using the microsatellite marker Satt288. These makers are promising in assisted selection for Asian soybean rust resistance.
\end{abstract}

Index terms: Glycine max, Phakopsora pachyrhizi, molecular markers, assisted selection.

\section{Introdução}

A expansão do cultivo da soja, observada desde sua introdução comercial no Brasil na década de 70, pode ser atribuída em grande parte ao melhoramento genético, que possibilitou o plantio em quase todo o território nacional e colocou a soja como a principal cultura da pauta de exportações brasileiras. Entretanto, com o avanço, surgem fatores limitantes à obtenção de maior produtividade, como o aumento de pragas e doenças, entre as quais se destaca a ferrugem-asiática. 
A ferrugem é causada pelo fungo Phakopsora pachyrhizi Syd. \& P. Syd. e ocorre no Hemisfério Leste desde 1902 (Sinclair \& Hartman, 1999). Foi relatada pela primeira vez no Brasil, no final da safra 2000/2001, no Paraná, tendo-se disseminado rapidamente por todo o país e ocasionado perdas superiores a $80 \%$ em áreas mais infectadas (Yorinori et al., 2005).

A obtenção de cultivares resistentes ao patógeno tem sido um desafio. Quatro genes dominantes, quanto à resistência, foram inicialmente descritos na literatura - Rpp1, Rpp2, Rpp3 e Rpp4 (Bromfield \& Hartwig, 1980; McLean \& Byth, 1980; Hartwig \& Bromfield, 1983; Hartwig, 1986); recentemente um novo loco de resistência (Rpp5) foi descrito por Garcia et al. (2008). Entretanto, a elevada variabilidade do patógeno reduz a eficiência da resistência vertical. No Brasil, as 11 cultivares resistentes, identificadas inicialmente tiveram a resistência quebrada por novas estirpes do fungo, provenientes do Mato Grosso, e apenas as fontes de resistência dos locos Rpp2 e Rpp4 permanecem eficientes (Yorinori et al., 2005).

O processo de seleção de genótipos resistentes pelas técnicas convencionais é relativamente demorado, além de laborioso e dependente de condições ambientais adequadas. Assim, a seleção assistida por marcadores moleculares é de grande utilidade, principalmente no processo de caracterização e seleção de genótipos resistentes, por ser um processo rápido e seguro para o desenvolvimento de novas cultivares superiores.

Dentre os marcadores existentes, destaca-se o RAPD (random amplified polymorphic DNA), baseado na amplificação de oligonucleotídeos de dez bases de seqüência aleatória, que apresenta como vantagens a rapidez e praticidade do método, necessidade de menores quantidades de DNA e baixo custo (Ferreira \& Grattapaglia, 1998). Essas características tornam o RAPD bastante interessante para a identificação de marcas moleculares ligadas a caracteres de interesse, como genes de resistência, com uso da técnica BSA (bulked segregant analysis), descrita por Michelmore et al. (1991), que consiste na amplificação por PCR (polimerase chain reaction) de dois conjuntos de indivíduos ("bulks"), com quantidades equimolares de DNA de plantas resistentes e suscetíveis, para detecção de marcadores polimórficos entre eles. Entretanto, algumas desvantagens do RAPD, como sua natureza dominante e a baixa reprodutibilidade, podem levar à necessidade de alternativas como a conversão em marcadores SCAR (sequence characterized amplified regions) (Kesseli et al., 1992; Ferreira \& Grattapaglia, 1998).

Diversos estudos identificaram marcadores RAPD ligados a genes de resistência a patógenos em várias culturas, entre eles: resistência ao nematóide-de-cistoda-soja, à mancha olho-de-rã, ao míldio e ao cancroda-haste em soja (Heer et al., 1998; Carvalho et al., 2002; Chowdhury et al., 2002; Martins Filho et al., 2002; Gavioli et al., 2007); resistência à manchaangular em feijoeiro (Ferreira et al., 1999); resistência à brusone em arroz (Araújo et al., 2004). Com relação à ferrugem-asiática, Hyten et al. (2007) identificaram dois marcadores microssatélites ligados ao gene Rppl, o Sct_187 e o Sat_064, e Silva et al. (2008) detectaram os iniciadores Sat_255 e Satt620, próximos ao gene $R p p 2$, e o Satt288 e o AF162283 próximos ao gene Rpp4.

Os objetivos deste trabalho foram confirmar a herança da resistência da PI 459025 ao patógeno causador da ferrugem-asiática-da-soja e identificar marcadores moleculares do tipo RAPD, ligados a este gene de resistência, em populações de soja.

\section{Material e Métodos}

O trabalho foi conduzido no Laboratório de Biotecnologia Aplicada ao Melhoramento de Plantas, do Departamento de Produção Vegetal, da Faculdade de Ciências Agrárias e Veterinárias da Unesp, Campus de Jaboticabal, SP, e na Empresa Tropical Melhoramento e Genética (TMG), em Cambé, PR.

Uma população originária do cruzamento PI 459025 (Bing Nam) x Coodetec 208, com 204 indivíduos, foi obtida na empresa TMG. A PI Bing Nam foi utilizada como fonte de resistência à ferrugem-asiática, enquanto a cultivar Coodetec 208 constituiu o material genético suscetível, adaptado às condições brasileiras.

Nos anos de 2005 e 2006, respectivamente, as gerações $F_{2}$ e $F_{2: 3}$ dessa população foram infectadas e avaliadas em casa de vegetação na TMG, quanto à resistência ao patógeno causador da ferrugem, conforme descrito por Garcia et al. (2008).

Para a semeadura, foram utilizados vasos de sete litros, com solo devidamente preparado, com três plantas em cada vaso, tendo-se mantido a correspondência de número utilizada nas duas gerações, de forma a possibilitar a identificação da presença ou ausência de 
segregação das progênies, oriundas de cada planta $\mathrm{F}_{2}$, pela observação do comportamento do patógeno nas progênies $F_{3}$.

Para a avaliação fenotípica da reação ao patógeno, foram realizadas inoculações com uma suspensão de esporos de P. pachyrhizi. O inóculo foi preparado a partir de folhas com pústulas em esporulação, que foram lavadas com auxílio de um pincel, em solução de água com $0,05 \%$ do espalhante adesivo Tween 20 , para a retirada dos esporos da superfície abaxial. As plantas foram pulverizadas com a suspensão ajustada para $10^{4}$ uredósporos por mililitro, com o auxílio de um hemocitômetro. A primeira inoculação foi realizada quando a planta atingiu o estádio $V_{2}$ da escala de Fehr \& Caviness (1977) e, posteriormente, foram feitas mais sete inoculações, em intervalos de quatro dias.

Após o aparecimento das pústulas, os genótipos foram avaliados e classificados, quanto à reação ao patógeno, pelo tipo de lesão apresentada, em que as plantas resistentes apresentaram a lesão do tipo RB, enquanto as suscetíveis apresentaram a lesão tipo TAN. Após a classificação de todos os indivíduos, os dados foram submetidos ao teste de qui-quadrado $\left(\chi^{2}\right)$, para verificação da segregação e determinação do tipo de herança do caráter. Os mesmos genótipos foram, ainda, avaliados nas famílias $\mathrm{F}_{2: 3}$, no ano seguinte, para confirmação das reações de resistência e diferenciação entre os genótipos homozigotos e heterozigotos, e observação da segregação do tipo de reação na progênie originária de cada indivíduo.

Antes da inoculação do fungo na geração $\mathrm{F}_{2}$, foram coletados trifólios de todos os indivíduos, que foram armazenados a $-80^{\circ} \mathrm{C}$, para posterior extração de DNA e utilização nas análises moleculares.

A extração de DNA de todas as plantas $F_{2}$, do referido cruzamento, foi realizada pelo método $\mathrm{CTAB}$ (brometo de cetil-trimetilamônio), descrito em Ferreira \& Grattapaglia (1998). As amostras de DNA foram quantificadas em biofotômetro, para verificação da quantidade de DNA presente na amostra, assim como sua qualidade, obtida pela relação entre as leituras a 260 e $280 \mathrm{~nm}$, em que o DNA de boa qualidade é indicado pela relação entre 1,8 e 2,0 (Sambrook \& Russell, 2001). A partir da quantificação, foram feitas as soluções de trabalho de DNA (30 ng $\left.\mu \mathrm{L}^{-1}\right)$ de todas as plantas.

A partir dos resultados das avaliações de resistência ao patógeno, na geração $F_{2}$, foram selecionados dez indivíduos resistentes e dez suscetíveis, todos comprovadamente homozigotos, conforme os resultados das avaliações da geração $F_{3}$. Quantidades equimolares de DNA desses indivíduos foram, então, utilizadas para montagem dos "bulks" a serem utilizados nas reações de PCR-RAPD, conforme a metodologia BSA de Michelmore et al. (1991).

Para as reações de PCR, com os iniciadores RAPD, foi utilizado um termociclador Mastercycler Gradient Eppendorf, com o programa de amplificação constituído de 42 ciclos de um min a $92^{\circ} \mathrm{C}$, para desnaturação do DNA, um min a $35^{\circ} \mathrm{C}$ para pareamento dos iniciadores, e dois min a $72^{\circ} \mathrm{C}$ para a extensão pela polimerase, tendo-se finalizado com 10 min a $72^{\circ} \mathrm{C}$ e estabilizado a $4^{\circ} \mathrm{C}$. As reações de amplificação com os RAPDs foram conduzidas conforme a metodologia de Williams et al. (1990), com 600 iniciadores da Operon Technologies (Alameda, CA, EUA). As reações com volume final de $25 \mu$ L consistiram de: tampão PCR $1 \mathrm{X}(10 \mathrm{mM}$ Tris- $\mathrm{HCl}$ $\mathrm{pH} 8,3$ e $50 \mathrm{mM} \mathrm{KCl}), 2,5 \mathrm{mM} \mathrm{MgCl}_{2}, 0,2 \mathrm{mM}$ dNTP, $45 \mathrm{ng}$ do iniciador, $120 \mathrm{ng}$ de DNA genômico, $1 \mathrm{U}$ de Taq polimerase e água Milli-Q. Os fragmentos amplificados foram, então, analisados por eletroforese a $100 \mathrm{~V}$ por cerca de uma hora, em gel de agarose $1,5 \%$ $(\mathrm{p} / \mathrm{v})$, corado com brometo de etídeo, em tampão TBE pH 8,0 (0,09 M de Tris, 0,09 $\mathrm{M}$ de ácido bórico e $2 \mathrm{mM}$ de EDTA). Os géis foram visualizados sob luz UV e fotografados com o sistema de fotodocumentação Kodak EDAS 290.

$O$ teste de qui-quadrado $\left(\chi^{2}\right)$ para a análise da segregação e determinação do tipo de herança da resistência, assim como a análise do co-segregação de cada marcador com o loco de resistência, foram feitos pelo programa Genes (Cruz, 2001). As freqüências de recombinação e estimativa das distâncias, entre os marcadores identificados e o loco de resistência, foram efetuadas pelo programa GQMOL (Cruz \& Schuster, 2008), tendo-se usado a distância de Kosambi, LOD score $>3$ e distância máxima de $30 \mathrm{cM}$, conforme Schuster \& Cruz (2004).

Com os resultados de estimativa das distâncias para todos os marcadores e o loco de resistência, procedeuse à construção de um mapa de ligação hipotético, com as melhores estimativas de ordenamento e distâncias, tendo-se considerado os três marcadores RAPD e o loco de resistência. O marcador microssatélite Satt288 foi adicionado às análises, para possibilitar o posicionamento dos marcadores e do loco de resistência 
no grupo de ligação do mapa físico do genoma da soja (Cregan et al., 1999; Song et al., 2004).

\section{Resultados e Discussão}

$\mathrm{Na}$ geração $\mathrm{F}_{2}$, foram observadas 43 plantas com lesão do tipo TAN (suscetível) e 158 com lesão tipo RB (resistente). Em três plantas, o tipo de lesão não foi identificado com segurança, e elas foram retiradas das análises (Tabela 1).

Nas avaliações fenotípicas da reação a $P$. pachyrhizi, realizadas na geração $F_{3}$, foi possível a confirmação das reações observadas na geração anterior $\mathrm{e}$, ainda, a identificação dos indivíduos homozigotos e heterozigotos da geração $\mathrm{F}_{2}$; esses resultados foram utilizados para testar a hipótese de segregação 1:2:1 (homozigoto resistente : heterozigoto : homozigoto suscetível) e, conseqüentemente, confirmar a herança monogênica com dominância completa na geração $F_{2}$. Nesse caso, a hipótese de segregação foi aceita, com probabilidade de $35,41 \%$ pelo teste de qui-quadrado, em que foram observadas 46 plantas homozigotas resistentes, 93 plantas heterozigotas e 58 plantas suscetíveis.

Outros estudos também confirmaram a presença de um gene dominante, que confere resistência à ferrugemasiática, em diferentes populações de soja oriundas de diversas fontes. Hyten et al. (2007) observaram a herança monogênica com dominância completa no gene Rppl na PI 200492. Silva et al. (2008) também detectaram a presença um gene dominante $(R p p 2)$, quanto à resistência à ferrugem, na PI 230970 e na PI459025 (Rpp4), este último é corroborado no presente estudo, que utilizou a mesma fonte de resistência. Com base nos trabalhos clássicos de descrição dos genes, realizados por Bromfield \& Hartwig (1980), McLean \& Byth (1980), Hartwig \& Bromfield (1983) e Hartwig (1986), e nos resultados obtidos, pode-se considerar o

Tabela 1. Número de plantas, com presença e ausência de bandas, nas reações de amplificação dos iniciadores OPBB-16, OPR-04 e OPAK-04, e resultados dos testes de $\chi^{2}$ na população de soja oriunda do cruzamento PI $459025 \mathrm{x}$ Coodetec 208, avaliada na geração $\mathrm{F}_{2}$.

\begin{tabular}{lccccc}
\hline Iniciadores RAPD & Presença & Ausência & GL & $\chi^{2}$ & Probabilidade $^{(1)}$ \\
\hline OPBB-16 & 70 & 27 & 1 & $0,4158^{\text {ns }}$ & 51,90 \\
OPAK-04 & 75 & 26 & 1 & $0,0297^{\text {ns }}$ & 86,32 \\
OPR-04 & 79 & 20 & 1 & $1,2155^{\text {ns }}$ & 27,02 \\
\hline ns Não-significativo. & ${ }^{(1)}$ Probabilidade em percentagem obtida no teste de $\chi^{2}$.
\end{tabular}

gene presente na população em estudo como sendo o Rpp4.

A reação dos genótipos $F_{2} \quad \mathrm{~F}_{2: 3}$ ao patógeno possibilitaram a composição dos "bulks" resistente e suscetível para a análise de BSAe para as reações de PCR com iniciadores RAPD para detecção de polimorfismo. A grande maioria dos 600 iniciadores testados se apresentou como monomórfica e não informativa, na diferenciação dos "bulks", e apenas 15 apresentaram polimorfismo entre os "bulks". Dos 15 iniciadores polimórficos, somente três (OPBB-16, OPAK-04 e OPR-04) apresentaram confirmação do polimorfismo, nas análises de plantas individuais dentro de cada "bulk", e foram então testados em todos os indivíduos da população.

Os três iniciadores identificados foram discriminativos, com suas respectivas marcas ligadas ao alelo recessivo de suscetibilidade (Figura 1). $\mathrm{O}$ iniciador OPBB-16 detectou um fragmento polimórfico de aproximadamente 650 pares de base presente no DNA do "bulk" suscetível, no parental suscetível Coodetec-208 e em todos os indivíduos pertencentes ao "bulk" suscetível, e foi ausente em todos os resistentes. O iniciador OPAK-04 detectou um fragmento polimórfico de cerca de 800 pares de base, também presente no "bulk" suscetível, na Coodetec-208 e em todos os indivíduos do "bulk" suscetível, e ausente nos resistentes. A mesma situação ocorreu com o iniciador OPR-04, que apresentou um fragmento polimórfico de cerca de 850 pares de base, com o mesmo comportamento dos dois marcadores citados anteriormente. Adicionalmente, oito cultivares brasileiras, suscetíveis à ferrugem-asiática (Coodetec 201,

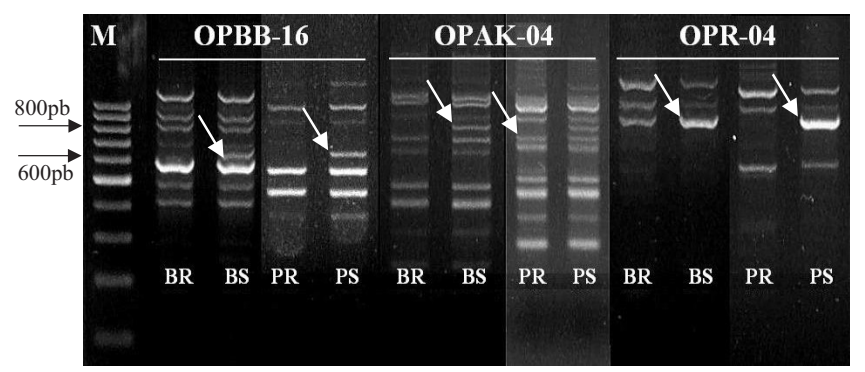

Figura 1. Marcadores RAPD com fragmentos polimórficos discriminativos quanto à resistência ao fungo Phakopsora pachyrhizi em soja. Na seqüência encontram-se o marcador de tamanho de bandas (M) e as reações do "bulk" resistente (BR), do "bulk" suscetível (BS), do parental resistente (PR) e do parental suscetível (PS), para cada iniciador. 
Coodetec 204, Ocepar-4, BRS-137, BR-16, FT Estrela, IAC-31 Foscarin, FT Cometa) foram testadas com os três iniciadores RAPD polimórficos detectados, cujos resultados confirmaram a presença das mesmas marcas, referidas anteriormente para cada iniciador (Figura 2).

O teste de qui-quadrado $\left(\chi^{2}\right)$ confirmou a segregação dos iniciadores polimórficos de 3:1 (presença da banda:ausência da banda), já que o marcador utilizado possui natureza dominante, e deve segregar conforme o esperado na herança mendeliana. Na Tabela 1, podem ser observados os resultados do $\chi^{2}$ dos três iniciadores detectados (OPBB-16, OPAK-04 e OPR-04), cuja hipótese de segregação testada foi confirmada.

Com relação ao teste de co-segregação de cada marcador com o loco de resistência, foi obtido o $\chi^{2}$ de 175,22 com OPBB-16, para a população em estudo, que foi altamente significativo $(\mathrm{p}<0,00001)$. Com o marcador OPAK-04 o $\chi^{2}$ foi 159,64, também altamente significativo $(p<0,00001)$. Finalmente,

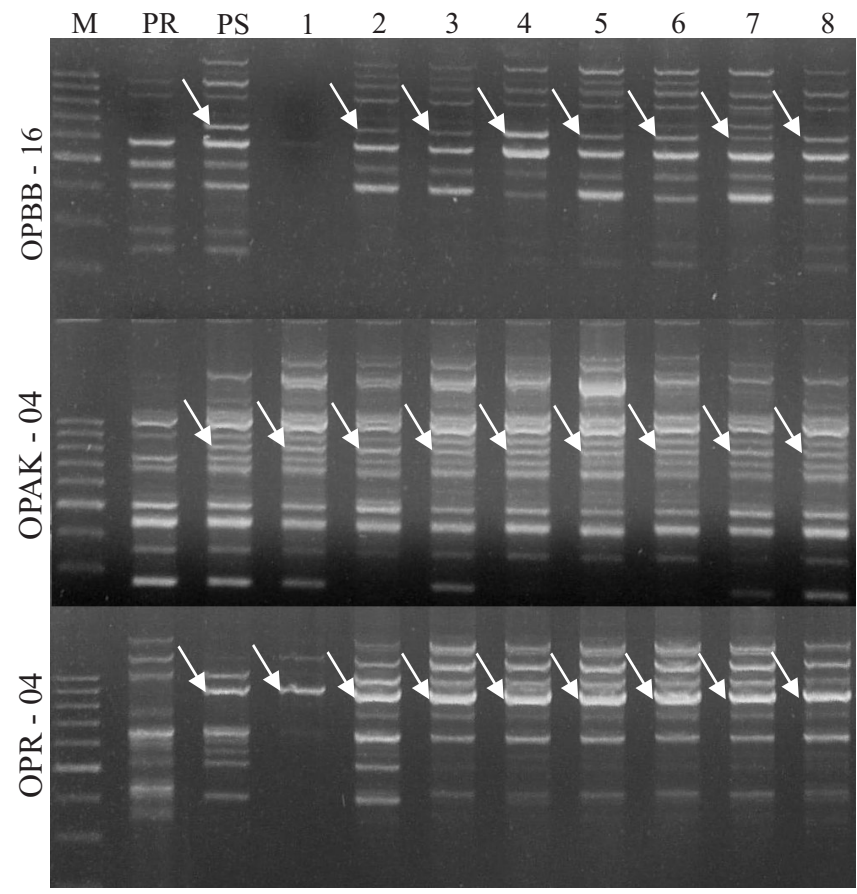

Figura 2. Reações com os marcadores RAPD OPBB-16, OPAK-04 e OPR-04, discriminativos quanto à resistência à ferrugem-asiática em cultivares de soja. $\mathrm{Na}$ seqüência, encontram-se o marcador de tamanho de bandas (M) e as reações do parental resistente (PR), do parental suscetível (PS) e de oito cultivares suscetíveis, para cada iniciador. Cultivares suscetíveis testadas: 1, Coodetec 201; 2, Coodetec 204; 3, Ocepar-4; 4, BRS-137; 5, BR-16; 6, FT Estrela; 7, IAC-31 Foscarin; e 8, FT Cometa. com o OPR-04, o $\chi^{2}$ foi $94,82(\mathrm{p}<0,0001)$, para a população. Todos os resultados significativos da segregação conjunta, com os três iniciadores, indicam que não ocorre segregação independente entre cada marcador e o loco, e há, assim, grande probabilidade de que eles estejam ligados. O marcador microssatélite Satt288 foi utilizado nas análises, por se encontrar ligado ao loco de resistência no genótipo PI 459025, o parental do presente ensaio, o que também foi observado por Silva et al. (2008). Nesse caso, o teste de co-segregação do Satt288 com o Rpp4 também foi altamente significativo ( $<<0,0001)$, com $\chi^{2}$ de 706,20 . Destaca-se, ainda, que a utilização do Satt288 confirma o posicionamento dos marcadores RAPD e do loco Rpp4, no grupo de ligação $\mathrm{G}$ do mapa físico do genoma da soja (Cregan et al., 1999; Song et al., 2004).

As análises de ligação, para a população avaliada, indicaram que, para OPBB-16, a distância entre o marcador e o loco de resistência, estimada a partir do fragmento polimórfico observado, foi de 5,1 $\pm 1,6 \mathrm{cM}$, com LOD escore de 33,16. Para o OPAK-04, a estimativa foi de $6,3 \pm 1,8 \mathrm{cM}$, com LOD escore de 30,52. Para o iniciador OPR-04, a distância estimada foi de $14,7 \pm 2,7 \mathrm{cM}$, com LOD escore de 17,95. Destaca-se, também, o marcador

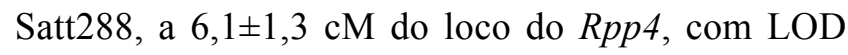
escore de 51,41. Os LOD escores calculados acima de 3 indicam a confiabilidade da hipótese de ligação entre os marcadores e o gene em estudo. A partir desses resultados, procedeu-se à construção do mapa de ligação, com o loco de resistência (Rpp4), os marcadores RAPD OPBB-16, OPAK-04 e OPR-04, além do Satt288 (Figura 3). A utilização do Satt288 posiciona o loco de resistência e os marcadores RAPD no grupo de ligação $G$ do mapa físico da soja.

Marcadores moleculares RAPD ligados a várias doenças têm sido identificados na cultura da soja. Entre esses, Carvalho et al. (2002) identificaram o marcador OPAB-19 como co-dominante, localizado a 4,7 cM de um gene de resistência ao cancro-dahaste. Chowdhury et al. (2002) identificaram dois marcadores ligados ao gene $\operatorname{Rpmx}$, de resistência ao míldio, denominados OPH-02 $2_{1250}$ e OPP- $10_{831}$, localizados respectivamente a 4,9 e $23,1 \mathrm{cM}$ do referido gene. Gavioli et al. (2007) detectaram um fragmento obtido pelo iniciador OPAB-04, a 7,4 cM de um gene de resistência ao cancro-da-haste. 
Com relação à ferrugem-asiática, Silva et al. (2008) identificaram marcadores SSR ligados a genes de resistência, em que se destacam o Satt288 e o

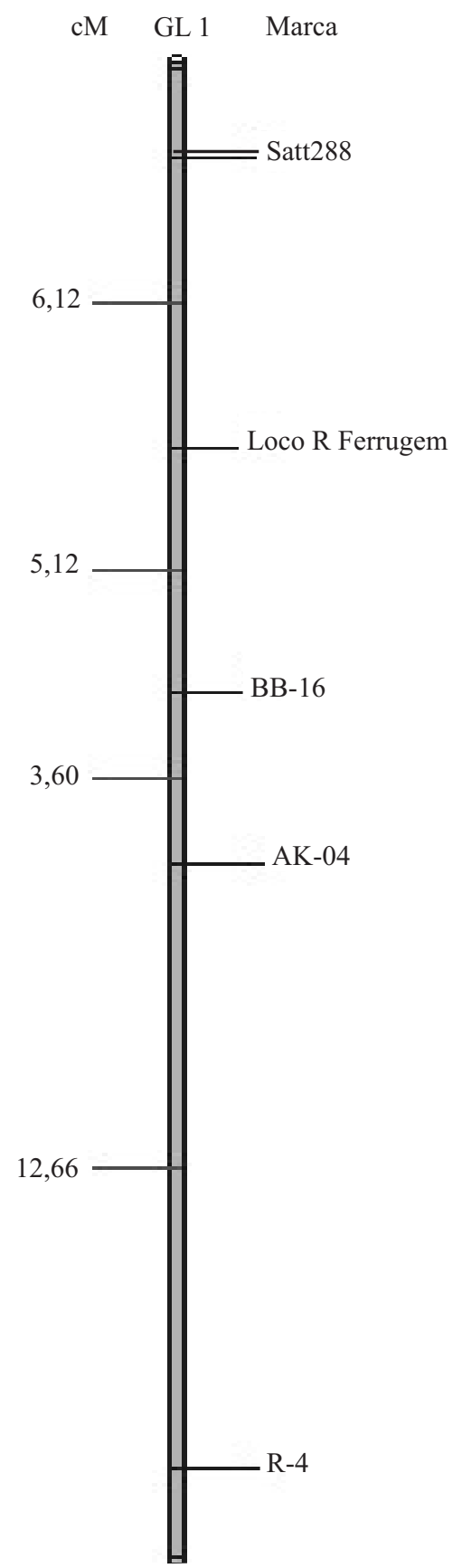

Figura 3. Mapa de ligação, com o melhor ordenamento e as distâncias estimadas (em cM) entre os marcadores RAPD (OPBB-16, OPAK-04 e OPR-04), o microssatélite Satt288 e o loco de resistência à ferrugem-asiáticada-soja (loco R Ferrugem).
AF162283, localizados a 1,9 e $12,8 \mathrm{cM}$ do gene Rpp4, respectivamente; e Sat_255 e Satt320, respectivamente a 7,3 e 5,6 cM do Rpp2. Hyten et al. (2007) localizaram o Sct_187 e o Sat_064, ao lado do gene Rppl a 4 cM.

Os resultados obtidos no presente estudo indicam a possibilidade de utilização dos marcadores RAPD OPBB-16, OPAK-04 e OPR-04, para a seleção assistida de genótipos resistentes ao fungo $P$. pachyrhizi, causador da ferrugem-asiática-da-soja, portadores da mesma fonte de resistência para os quais eles foram identificados, que devem ser validados na tentativa de uso para outras populações. Os resultados positivos, obtidos no teste de outras cultivares suscetíveis aleatórias (Coodetec 201, Coodetec 204, Ocepar-4, BRS-137, BR-16, FT Estrela, IAC-31 Foscarin, FT Cometa), confirmam a validade de utilização desses marcadores.

Ainda com relação a esses marcadores, deve-se considerar o fato de as marcas para os três iniciadores estarem ligadas ao loco de resistência em fase de repulsão, de tal forma que o alelo dominante do marcador (presença da banda) está ligado ao alelo recessivo do gene (suscetibilidade), e o alelo dominante do gene (resistência) está ligado ao alelo recessivo do marcador (ausência da banda). Isso impossibilita a separação entre os indivíduos suscetíveis e os resistentes heterozigotos, de forma que apenas os resistentes homozigotos podem ser diretamente selecionados, pela ausência das marcas. Nesse caso, pode ser sugerida a utilização, em duas gerações consecutivas, de modo que possam ser separados os heterozigotos pela segregação da última geração.

\section{Conclusões}

1. A resistência à ferrugem-asiática-da-soja é governada por um gene de ação dominante no genótipo PI 459025.

2. Os iniciadores RAPD OPBB-16, OPAK-04 e OPR-04 são indicados para seleção assistida, em genótipos de soja com a mesma fonte de resistência do presente estudo.

\section{Agradecimentos}

À Fundação de Amparo à Pesquisa do Estado de São Paulo, por concessão de bolsa e auxílio financeiro; à Empresa Tropical Melhoramento e Genética (TMG), pela oportunidade de parceria na condução das pesquisas. 


\section{Referências}

ARAÚJO, L.G.; PRABHU, A.S.; PEREIRA, P.A.A. RAPD marker linked to a gene conferring resistance to race IB-9 of Pyricularia grisea in a somaclone of the rice cultivar Araguaia. Plant Cell, Tissue and Organ Culture, v.78, p.151-158, 2004.

BROMFIELD, K.R.; HARTWIG, E.E. Resistance to soybean rust and mode of inheritance. Crop Science, v.20, p.254-255, 1980.

CARVALHO, G.A.; SEDIYAMA, T.; ALZATE-MARIN, A.L.; BARROS, E.G.; MOREIRA, M.A. Identificação de marcadores RAPD ligados a um gene de resistência ao cancro-da-haste-dasoja. Fitopatologia brasileira, v.27, p.474-478, 2002.

CHOWDHURY, A.K.; SRINIVES, P.; SAKSOONG, P.; TONGPAMNAK, P. RAPD markers linked to resistance to downy mildew disease in soybean. Euphytica, v.128, p.55-60, 2002.

CREGAN, P.B.; JARVIK, T.; BUSH, A.L.; SHOEMAKER, R.C.; LARK, K.G.; KAHLER, A.L.; KAYA, N.; VANTOAI, T.T.; LOHNES, D.G.; CHUNG, L.; SPECHT, J.E. An integrated genetic linkage map of the soybean genome. Crop Science, v.39, p.1464-1490, 1999.

CRUZ, C.D. Programa Genes: versão Windows: aplicativo computacional em genética e estatística. Viçosa: Editora da UFV, 2001. 648p.

CRUZ, C.D.; SCHUSTER, I. GQMOL: aplicativo computacional para análise de dados moleculares e de suas associações com caracteres quantitativos: versão 2008. Disponível em: <http:// www.ufv.br/dbg/gqmol/gqmol.htm>. Acesso em: 14 abr. 2008.

FEHR, W.R.; CAVINESS, J.A. Stages of soybean development. Aimes: Iowa State University, 1977. 11p. (Special Report, 80).

FERREIRA, M.E.; GRATTAPAGLIA, D. Introdução ao uso de marcadores moleculares em análise genética. 3ed. Brasília: Embrapa-Cenargen, 1998. 220p.

FERREIRA, C.F.; BORÉM, A.; CARVALHO, G.A.; NIETSCHE, S.; PAULA JÚNIOR, T.J.; BARROS, E.G.; MOREIRA, M.A. Identificação de marcador RAPD ligado ao gene de resistência à raça 63.39 da mancha-angular do feijoeiro. Bragantia, v.58, p.247-252, 1999.

GARCIA, A.; CALVO, E.S.; KIIHL, R.A.S.; HARADA, A.; HIROMOTO, D.M.; VIEIRA, L.G.E. Molecular mapping of soybean rust (Phakopsora pachyrhizi) resistance genes: discovery of a novel locus and alleles. Theoretical and Applied Genetics, v.117, p.545-553, 2008.

GAVIOLI, E.A.; MAURO, A.O.; CENTURION, M.A.P.C.; MAURO, S.M.Z. Development of SCAR marker linked to stem canker resistance gene in soybean. Crop Breeding and Applied Biotechnology, v.7, p.133-140, 2007.

HARTWIG, E.E. Identification of a fourth major gene conferring resistance to rust in soybean. Crop Science, v.26, p.1135-1136, 1986.

HARTWIG, E.E.; BROMFIELD, K.R. Relationships among three genes conferring specific resistance to rust in soybeans. Crop Science, v.23, p.237-239, 1983.

HEER, J.A.; KNAP, H.T.; MAHALINGAM, R.; SHIPE, E.R.; ARELLI, P.R.; MATTHEWS, B.F. Molecular markers for resistance to Heterodera glycines in advanced soybean germplasm. Molecular Breeding, v.4, p.359-367, 1998.

HYTEN, D.L.; HARTMAN, G.L.; NELSON, R.L.; FREDERICK, R.D.; CONCIBIDO, V.C.; NARVEL, J.M.; CREGAN, P.B. Map location of the Rppl locus that confers resistance to soybean rust in soybean. Crop Science, v.47, p.837-840, 2007.

KESSELI, R.V.; PARAN, I.; MICHELMORE, R.W. Efficient mapping of specifically targeted genomic regions and the tagging of these regions with reliable PCR-based genetic markers. In: APPLICATIONS OF RAPD TECHNOLOGY TO PLANT BREEDING, 1992, Minneapolis. Proceedings... Madison, WI: ASA, 1992. p.31-36.

MARTINS FILHO, S.; SEDIYAMA, C.S.; MOREIRA, M.A.; BARROS, E.G. RAPD and SCAR markers linked to resistance to frogeye leaf spot in soybean. Genetics and Molecular Biology, v.25, p.317-321, 2002.

McLEAN, R.J.; BYTH, D.E. Inheritance of resistance to rust (Phakopsora pachyrhizi) in soybeans. Australian Journal of Agricultural Research, v.31, p.951-956, 1980.

MICHELMORE, R.W.; PARAN, I.; KESSELI, R.V. Identification of markers linked to disease-resistance genes by bulked segregant analysis: a rapid method to detect markers in specific genomic regions by using segregation populations. Proceedings of the National Academy of Sciences USA, v.88, p.9828-9832, 1991.

SAMBROOK, J.; RUSSELL, D.W. Molecular cloning: a laboratory manual. 3.ed. New York: Cold Spring Harbor Laboratory Press, 2001.

SCHUSTER, I.; CRUZ, C.D. Estatística genômica aplicada a populações derivadas de cruzamentos controlados. Viçosa: Editora da UFV, 2004. 568p.

SILVA, D.C.G.; YAMANAKA, N.; BROGIN, R.L.; ARIAS, C.A.A.; NEPOMUCENO, A.L.; MAURO, A.O.; PEREIRA, S.S.; NOGUEIRA, L.M.; PASSIANOTTO, A.L.L.; ABDELNOOR, R.V. Molecular mapping of two loci that confer resistance to Asian rust in soybean. Theoretical and Applied Genetics, v.117, p.57-63, 2008.

SINCLAIR, J.B.; HARTMAN, G.L. Soybean rust. In: HARTMAN, G.L.; SINCLAIR, J.B.; RUPE, J.C. (Ed.). Compendium of soybean diseases. 4ed. St. Paul: American Phytopathological Society, 1999. p.3-4.

SONG, Q.J.; MAREK, L.F.; SHOEMAKER, R.C.; LARK, K.G.; CONCIVIDO, V.C.; DELANAY, X.; SPECHT, J.E.; CREGAN, P.B. A new integrated genetic linkage map of the soybean. Theoretical and Applied Genetics, v.109, p.122-128, 2004.

WILLIAMS, J.G.; KUBELIK, A.R.; LIVAK, K.J.; RAFALSKI, L.A.; TINGEY, S.V. DNA polymorphism amplified by arbitrary primers are useful as genetic markers. Nucleic Acids Research, v.18, p.6531-6535, 1990.

YORINORI, J.T.; PAIVA, W.M.; FREDERICK, R.D.; COSTAMILAN, L.M.; BERTAGNOLI, P.F.; HARTMAN, G.L.; GODOY, C.V.; NUNES, J.J. Epidemics of soybean rust (Phakopsora pachyrhizi) in Brazil and Paraguay from 2001 to 2003. Plant Disease, v.89, p.675-677, 2005.

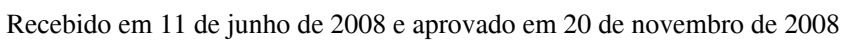

